\title{
Utilization and associated factors of reproductive health services among 20-39-year-old women in rural China: a cross-sectional study
}

Jing Yue, Yang Luo*, Chen Xu, Si Qin, Yanting Meng, Ling Fan and Min Nie

\begin{abstract}
Background: The use of reproductive health $(\mathrm{RH})$ services is important to promote $\mathrm{RH}$. However, little is known about RH services in rural areas, especially in low- and middle-income countries. China is the most populous country in the world, and $40.4 \%$ of its population is rural. Our study determined the utilization of and factors associated with $\mathrm{RH}$ services in rural China.

Methods: A cross-sectional study of 978 20- to 39-year-old women was performed in four villages of four cities in Hunan Province. A researcher-created structured questionnaire was used to collect the data. The data were entered into EpiData v3.0 and analysed using SPSS v18.0. Statistical significance was defined as a two-sided $P$-value of less than 0.05. Descriptive statistics were used to examine the socio-demographic factors and the use of RH services by the sample population. Chi-square tests were used to assess associations between categorical variables. Logistic regression analyses were performed to examine factors that correlated with the use of RH services.
\end{abstract}

Results: The top three services used were antenatal examinations (90.2\%), postpartum visits (73.0\%) and free folic acid supplements (71.6\%). Age, monthly household income, employment, spousal education level, and artificial abortion history were associated with RH service utilization $(P<0.05)$. The most desired $\mathrm{RH}$ service was cervical/breast cancer prevention services (58.9\%). The most preferred method participants used to obtain information on $\mathrm{RH}$ services was the internet.

Conclusions: The utilization rate for RH services in rural China needs improvement. Future efforts should target highrisk populations of women by providing them with $\mathrm{RH}$-related information and cultivating positive attitudes towards $\mathrm{RH}$ services.

\section{Plain language summary}

Reproductive health $(\mathrm{RH})$ services are recognized worldwide as a cost-effective strategy to promote $\mathrm{RH}$. However, little is known about RH services in rural areas, especially in low- and middle-income countries. China is the most populous country in the world, and $40.4 \%$ of its population is rural. Due to the implementation of China's universal two-child policy, women between 20 and 39 years old are likely to experience more $\mathrm{RH}$ problems related to childbirth. Our

*Correspondence: ly603202@csu.edu.cn

Xiang Ya Nursing School, Central South University, Changsha, China permits use, sharing, adaptation, distribution and reproduction in any medium or format, as long as you give appropriate credit to the original author(s) and the source, provide a link to the Creative Commons licence, and indicate if changes were made. The images or other third party material in this article are included in the article's Creative Commons licence, unless indicated otherwise in a credit line to the material. If material is not included in the article's Creative Commons licence and your intended use is not permitted by statutory regulation or exceeds the permitted use, you will need to obtain permission directly from the copyright holder. To view a copy of this licence, visit http://creativecommons.org/licenses/by/4.0/. The Creative Commons Public Domain Dedication waiver (http://creativeco mmons.org/publicdomain/zero/1.0/) applies to the data made available in this article, unless otherwise stated in a credit line to the data. 
study investigated the utilization of and factors associated with $\mathrm{RH}$ services in rural China. The top three services used among the 978 participants were antenatal examinations (90.2\%), postpartum visits (73.0\%) and free folic acid supplements (71.6\%). Age, monthly household income, employment, spousal education level, and artificial abortion history were associated with $\mathrm{RH}$ service utilization. The participants most desired services pertained to the prevention of cervical/breast cancer, and the most preferred methods used to obtain information related to $\mathrm{RH}$ services was the internet.

In conclusion, the utilization of RH services requires improvement, and future efforts should target high-risk populations of women by providing them with RH-related information and cultivating positive attitudes towards $\mathrm{RH}$ services.

Keywords: Reproductive health, Service, Utilization, Rural, China

\section{Background}

Reproductive health $(\mathrm{RH})$ refers to a state of complete physical, mental, and social well-being (and not merely the absence of disease or infirmity) in all matters relating to the reproductive system and its functions and processes [1]. RH is closely related to human reproduction and social development $[2,3]$. RH services refer to the medical and health services provided for the realization of reproductive health, including sex education, sexual and reproductive health consultation, contraceptives, and medical and health services [4]. The United Nations (UN) Sustainable Development Goals (SDGs) include ensuring universal access to sexual and reproductive health care services by 2030 [5]. Therefore, it is necessary to identify the uses and obstacles of $\mathrm{RH}$ services.

A total of 3.4 billion people live in rural areas worldwide, representing $44.0 \%$ of the global population [6]. China is the most populous country in the world, and the rural population accounts for $40.4 \%$ of its total population. One study in rural China showed that $53 \%$ of the respondents had a low RH knowledge score, and 39\% of respondents with gynecopathy-related discomfort did not seek professional help [7]. Since the implementation of the universal two-child policy in 2016, every couple in China has been encouraged to have two children [8]. The number of women between 20 and 39 years old choosing to give birth increased rapidly in a short time. $\mathrm{RH}$ problems related to childbirth have also become more prominent $[9,10]$. Women between 20 and 39 years old are likely to experience more $\mathrm{RH}$ problems related to childbirth. Therefore, identifying the uses of $\mathrm{RH}$ services and the factors influencing their use are urgently needed.

Although some studies have examined the use of RH services in Chinese women, there are still some limitations of the available studies [11-15]. Some of the problems we observed in our review were that studies were conducted before the implementation of the universal two-child policy, obtained samples from medical units, and did not analyse associated factors very well. Our study targeted large-scale community women aged 20-39 years to investigate the utilization and associated factors of $\mathrm{RH}$ services in rural areas after implementation of the universal two-child policy. We also determined the desired RH services and preferred methods of obtaining RH-related information in rural women. These findings will be useful for the implementation of policies and strategies that promote the use of $\mathrm{RH}$ services in rural areas.

\section{Methods \\ Study design and sampling}

This cross-sectional study was performed in Hunan Province in cooperation with the Women's Federation of the Hunan Provincial Government between May 30 and September 16, 2019. Hunan Province is a major province in central China with a rural population of 30.3 million. The birth rate in 2018 was the highest of the three regions of China (i.e., western, central, and eastern China) at $1.2 \%$ compared with $1.0 \%$ in eastern China and $1.1 \%$ in western China [16]. We selected four counties in the eastern (Loudi), western (Huaihua), southern (Chenzhou), and northern (Changde) regions of Hunan Province that were representative of each region based on economic and demographic factors. We then selected one city in each county. Multistage cluster sampling was used to recruit participants from the four selected cities. We randomly selected one township per city and one village from each township for a total of four villages.

\section{Sample size}

We determined the sample size using a random sampling formula. A study of the floating population estimated that the utilization rate of RH services in China was approximately $40.0 \%$ [17], and we chose an approximate value of $40.0 \%$ to calculate the sample size. The following formula was used to calculate the sample size: $\mathbf{n}=\boldsymbol{\mu}^{2}{ }_{\alpha} \times \mathbf{P}(\mathbf{1 - P}) /$ $\boldsymbol{\delta}^{2}$, where $\alpha=0.05, \mu_{\alpha}=1.96$, P was the overall rate of $\mathrm{RH}$ service use, and $\delta=3.3 \%$. The calculated sample size was 847. To reduce sampling error and increase the study power, we made a rough estimation by arbitrarily multiplying the calculated sample size by $15 \%$, which led to a sample size of 974 . Ultimately, 980 women who met the 
requirements were recruited, and 978 (99.8\%) participants completed the questionnaire as requested.

\section{Participants}

Dynamic population monitoring data (marriage, pregnancy, birth, death and migration), which were collected and updated regularly by the health department from Hunan Province, revealed that the fertility rate of women over 40 years was less than $2.0 \%$ [18]. Therefore, women aged 20-39 years were selected in our study to investigate the utilization of and factors associated with RH services. The inclusion criteria were: (1) females between 20 and 39 years old, (2) females with residence registration (hukou) in rural Hunan or who had lived in the investigated area for more than 6 months, and (3) females who provided oral informed consent. The exclusion criteria were cognitive impairment and the inability to complete the questionnaire independently. All participants were told that their involvement was voluntary and that they could withdraw at any time.

\section{Measurements and data collection}

The Women's Reproductive Health Questionnaire (WRH-Q) was developed by the researchers after an extensive literature review and revised by a panel of 10 experts from Central South University, affiliated hospitals, and the Hunan Women's Federation (see Additional file 1). We recruited women via direct door-to-door visits. When three door-to-door visits failed (because the subjects were out of the house or refused to participate), the household was abandoned and replaced with an alternate household in sequence.

The Women's Federation of the Hunan Provincial Government trained community health workers who were familiar with the locality as investigators. The training content included the content and purpose of the current study and the process for collecting the questionnaires. Well-trained investigators performed interviews with eligible subjects and explained the study purpose and procedures. The anonymous questionnaires were completed by the subjects themselves or with the help of the investigators if the subjects had limited literacy. Personnel from the local maternal and child health facility acted as auditors and were responsible for questionnaire collection and quality control. Auditors assessed the completeness and accuracy of each questionnaire on the spot and asked for additional information or corrections if any omissions or errors were found.

\section{Socio-demographic and gestation data}

We collected information on each participant's age, marital status, employment, monthly household income, education level, spouse's education level, sexually active status, artificial abortion history, pregnancy history, and delivery history.

\section{Utilization of RH services}

$\mathrm{RH}$ services for women of childbearing age in China primarily include consultations, premarital check-ups, preconception care, antenatal examinations, postpartum visits, and general gynaecological examinations [16]. The questionnaire collected the following information: (1) utilization of RH counselling, in which participants answered questions about whether they received contraception and/or pregnancy counselling; (2) utilization of $\mathrm{RH}$-related examinations or services, in which participants answered questions on whether they received free folic acid supplements; free AIDS, syphilis and hepatitis B testing; free antenatal examinations; free preconception care; and free postpartum visits; and (3) utilization of RH screening, in which participants answered questions regarding whether they received cervical and breast cancer screening. Participants who used all RH counselling/RH screening services and four or more $\mathrm{RH}$-related examinations/services were categorized as participants who sufficiently utilized RH services.

\section{Needs for RH services}

The structured questionnaire also asked about the women's needs for RH services. (1) What type of RH services do you desire to receive? (Options: prevention of cervi$\mathrm{cal} /$ breast cancer, child health care, reproductive tract infection/sexually transmitted disease treatment, psychological health care, pregnancy/prenatal care, contraception, menstrual hygiene, and others). (2) What method do you prefer to use to obtain RH service-related information? (Options: medical staff, internet, WeChat/ microblogs, radio and television, friends and family, books/newspapers/magazines, and brochures).

\section{Data analysis}

All data were assessed for errors and double-entered independently into EpiData (Version 3.0., The Epidata Association, Odense, Denmark). Data were analysed using SPSS (Version 18.0., Chicago: SPSS Inc.). Descriptive statistics were used to examine the socio-demographic factors and status of the RH services used by the participants. Differences in the use of RH services between different groups (e.g., age, employment, monthly household income, education level and spouse's education level, and artificial abortion history) were computed using the chi-square test. Logistic regression analyses were performed to examine factors that correlated with the use of RH services. Statistical significance was defined as a two-sided $P$-value less than 0.05 . If greater 
than $20 \%$ of the items had missing values, the questionnaire was excluded as invalid.

\section{Ethical considerations}

The Ethics Committee of Xiang Ya Nursing School, Central South University approved the study (approval number: 2019005). Written consent was obtained from all respondents before the interviews.

\section{Results}

\section{Participants' socio-demographic and gestational characteristics}

Among the 980 women who were recruited in this study, 978 completed the questionnaire as requested (response rate: $99.8 \%$ ). Of the 978 women, most of the respondents were married (86.5\%), and their average age was 30.2 years $(\mathrm{SD}=4.9)$. Of the 850 women who were sexually active, 820 had a history of pregnancy (96.5\%). Among the 820 women with a history of pregnancy, 257 had a history of artificial abortion (31.4\%), and 811 women had a history of delivery (98.9\%) (Table 1).

\section{Utilization of RH services}

Of the 850 women who were sexually active, 53.6\% received contraception counselling. Among the 820 women who had given birth, $27.5 \%$ received free preconception care, and $90.2 \%$ received free antenatal examinations. Of the 978 women, approximately one-third received cervical and breast cancer screening (Table 2).

\section{Factors associated with the use of RH services}

Table 3 presents the results of the univariate analysis of differences in the use of $\mathrm{RH}$ services in different groups. Statistically significant differences $(P<0.05)$ in the use of $\mathrm{RH}$ screening and $\mathrm{RH}$ examinations/services were noted based on age, employment, monthly household income and spouse education level. There were statistically significant differences $(P<0.05)$ in the use of RH counselling based on employment and artificial abortion history.

Table 4 presents the results of the logistic regression analysis on the relationship between the associated factors and $\mathrm{RH}$ service utilization. Compared with women aged 19-29, 30-39-year-old women were more likely

Table 1 Socio-demographic and gestational characteristics $(N=978)$

\begin{tabular}{|c|c|c|c|}
\hline Variables & Categories & Frequencies & Percentages \\
\hline \multirow[t]{3}{*}{ Age (years) } & $19-25$ & 186 & 19.0 \\
\hline & $26-32$ & 435 & 44.5 \\
\hline & $33-39$ & 357 & 36.5 \\
\hline \multirow[t]{2}{*}{ Marital status } & Unmarried & 132 & 13.5 \\
\hline & Married & 846 & 86.5 \\
\hline \multirow[t]{2}{*}{ Employment } & Unemployed & 347 & 35.5 \\
\hline & Employed & 631 & 64.5 \\
\hline \multirow[t]{3}{*}{ Monthly household income ('USD) } & $<771$ & 625 & 63.9 \\
\hline & $771-1543$ & 322 & 32.9 \\
\hline & $>1543$ & 31 & 3.2 \\
\hline \multirow[t]{4}{*}{ Education level } & Primary school or less & 53 & 5.4 \\
\hline & Junior high school & 388 & 39.7 \\
\hline & Senior high school & 295 & 30.2 \\
\hline & College or more & 242 & 24.7 \\
\hline \multirow[t]{4}{*}{ Spouse's education level $(\mathrm{N}=846)$} & Primary school or less & 41 & 4.8 \\
\hline & Junior high school & 332 & 39.3 \\
\hline & Senior high school & 293 & 34.6 \\
\hline & College or more & 180 & 21.3 \\
\hline \multirow[t]{2}{*}{ Sexually active } & No & 128 & 13.1 \\
\hline & Yes & 850 & 86.9 \\
\hline \multirow[t]{2}{*}{ Pregnancy history $(\mathrm{N}=850)$} & No & 30 & 3.5 \\
\hline & Yes & 820 & 96.5 \\
\hline \multirow[t]{2}{*}{ Artificial abortion history $(\mathrm{N}=820)$} & No & 563 & 68.6 \\
\hline & Yes & 257 & 31.4 \\
\hline \multirow[t]{2}{*}{ Delivery history $(\mathrm{N}=820)$} & No & 9 & 1.1 \\
\hline & Yes & 811 & 98.9 \\
\hline
\end{tabular}

* 1 USD $\approx 6.5$ RMB (January 24, 2021) 
Table 2 Utilization of $\mathrm{RH}$ services $(\mathrm{N}=978)$

\begin{tabular}{lll}
\hline Variables & Frequencies & Percentages \\
\hline RH counselling $(n=850)$ & & \\
Contraception counselling & 456 & 53.6 \\
Pregnancy counselling & 303 & 35.7 \\
$R H$ screening & & \\
Cervical cancer screening & 359 & 36.7 \\
Breast cancer screening & 333 & 34.0 \\
RH examinations/services $(n=820)$ & & \\
Free folic acid supplement & 587 & 71.6 \\
Free AlDS, syphilis and hepatitis B testing & 389 & 47.5 \\
Free antenatal examination & 740 & 90.2 \\
Free preconception care & 225 & 27.5 \\
Free postpartum visit & 599 & 73.0 \\
\hline
\end{tabular}

to use $\mathrm{RH}$ screening (OR $=1.985,95 \% \mathrm{CI}$ : $1.555-2.533)$ but were less likely to use RH-related examinations/ services (OR $=0.710,95 \%$ CI: 0.513-0.983). Compared with women who were unemployed, employed women were more likely to use $\mathrm{RH}$ counselling $(\mathrm{OR}=1.678$, 95\% CI: $1.138-2.476), \mathrm{RH}$ screening $(\mathrm{OR}=2.060,95 \%$ CI: 1.504-2.821), and RH-related examinations/services $(\mathrm{OR}=1.510,95 \% \mathrm{CI}: 1.035-2.205)$. Compared with women whose monthly household income was less than 771 USD, women with monthly household income between 771 and 1543 USD were more likely to use RH screening ( $\mathrm{OR}=1.681,95 \% \mathrm{CI}: 1.320-2.142)$. Compared with women whose spouse's education level was junior high school or less, women with a higher spouse's education level were more likely to use RH screening $(\mathrm{OR}=1.335,95 \% \mathrm{CI}: 1.009-1.765$; OR $=1.649,95 \% \mathrm{CI}$ : 1.233-2.204, respectively) and RH-related examinations/ services $(\mathrm{OR}=1.675,95 \% \mathrm{CI}: 1.115-2.515$; $\mathrm{OR}=1.976$, 95\% CI: $1.313-2.973$, respectively). Women who had a history of artificial abortion were more likely to use RH counselling ( $\mathrm{OR}=2.743,95 \% \mathrm{CI}$ : $2.081-3.615)$.

\section{Participants most desired RH services}

The top three $\mathrm{RH}$ services participants most desired were prevention of cervical/breast cancer (58.9\%), child health care $(48.2 \%)$, and reproductive tract infection/sexually transmitted disease treatment (41.1\%) (Fig. 1).

\section{The most preferred methods to obtain RH service-related information}

The top three methods participants preferred to use to obtain $\mathrm{RH}$ service-related information were the internet
(54.8\%), medical staff (54.4\%), and WeChat/microblogs (36.1\%) (Fig. 2).

\section{Discussion}

The total proportion of females receiving $\mathrm{RH}$ services in rural China needs improvement. Age, monthly household income, employment, spouse education level, and artificial abortion history were associated with the use of $\mathrm{RH}$ services. The RH services women most desired pertained to the prevention of cervical/breast cancer. The most preferred method for participants to obtain information about RH services was the internet.

The most commonly used RH service was antenatal examinations $(90.2 \%)$ in our study, demonstrating that the policy of promoting free antenatal examinations in China has achieved some success. The Chinese government stipulates that employed women are entitled to antenatal examination leave after pregnancy to give them more access to medical care [19]. However, the use of this service was below the national level of $95.0 \%$ [16]. This lower rate of use may be due to the increased proportion of older pregnant women under implementation of the universal two-child policy. These older women had multiple pregnancies and were less concerned about maternal and infant health due to poor risk awareness and successful experiences with previous pregnancies [20,21].

The second most commonly used $\mathrm{RH}$ service was postpartum visits (73.0\%). However, the Chinese health authorities state that the proportion of women engaging in postpartum visits after 2015 should be greater than 95.0\% [16]. The United States and some developing countries also have barriers to participation in postpartum visits, such as a negative attitude on the part of the providers and a lack of awareness of postpartum care [12, 22]. This finding indicates a need for health care facilities and providers to make concerted efforts to increase knowledge about the importance of postpartum visits and develop interventions for the target population, including education, home visits, incentives, and appointment scheduling initiatives [23, 24].

The third most commonly used RH service was free folic acid supplements (71.6\%), which was far below the national level of $95.0 \%$ [25]. Although the community provides free folic acid to every woman who desires to become or is already pregnant, most women think they do not need folic acid if they have a healthy pregnancy and think it is inconvenient to obtain folic acid from the community, as noted in a mixed-method study [26]. Therefore, the establishment of a more flexible method of folic acid delivery may facilitate folic acid supplementation. For example, all pregnant women without contraindications can receive a free folic acid supplement at a nearby pharmacy [27]. 


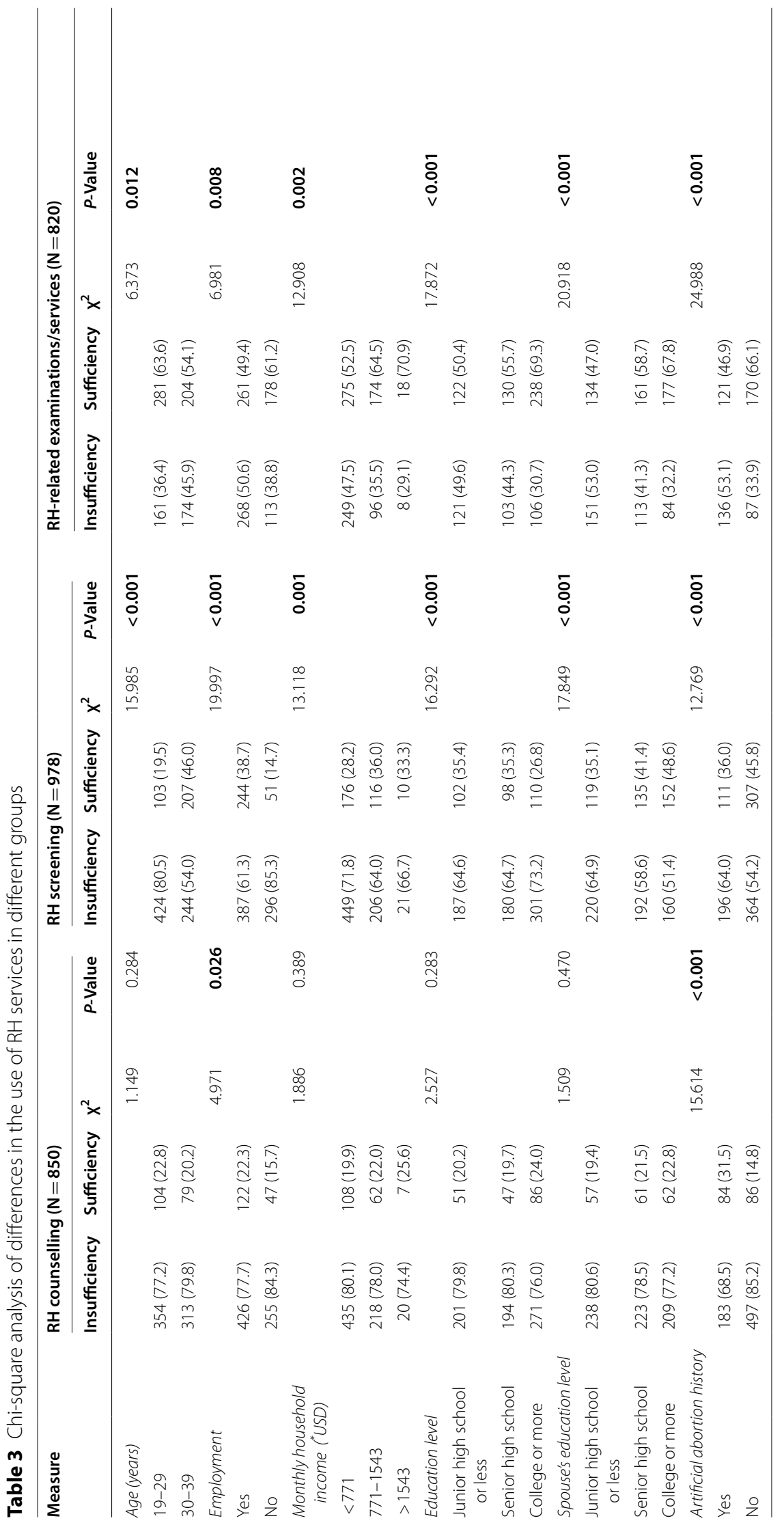


Table 4 Logistic regression analysis for factors associated with the use of RH services

\begin{tabular}{|c|c|c|c|c|c|c|c|c|c|}
\hline \multirow[t]{2}{*}{ Measure } & \multicolumn{3}{|c|}{ RH counselling $(\mathrm{N}=850)$} & \multicolumn{3}{|c|}{ RH screening $(\mathrm{N}=978)$} & \multicolumn{3}{|c|}{$\begin{array}{l}\text { RH-related examinations/services } \\
(\mathrm{N}=\mathbf{8 2 0})\end{array}$} \\
\hline & Coefficient & OR $(95 \% \mathrm{Cl})$ & $P$-Value & Coefficient & OR $(95 \% \mathrm{Cl})$ & $P$-Value & Coefficient & OR $(95 \% \mathrm{Cl})$ & $P$-Value \\
\hline \multicolumn{10}{|l|}{ Age (years) } \\
\hline $19-29$ & 1 & & & 1 & & & 1 & & \\
\hline $30-39$ & -0.256 & $\begin{array}{l}0.774(0.581- \\
1.032)\end{array}$ & 0.081 & 0.686 & $\begin{array}{l}1.985(1.555- \\
2.533)\end{array}$ & $<0.001$ & -0.342 & $\begin{array}{l}0.710(0.513- \\
0.983)\end{array}$ & 0.039 \\
\hline \multicolumn{10}{|l|}{ Employment } \\
\hline No & 1 & & & 1 & & & 1 & & \\
\hline Yes & 0.518 & $\begin{array}{l}1.678(1.138- \\
2.476)\end{array}$ & 0.009 & 0.723 & $\begin{array}{l}2.060(1.504- \\
2.821)\end{array}$ & $<0.001$ & 0.412 & $\begin{array}{l}1.510(1.035- \\
2.205)\end{array}$ & 0.033 \\
\hline \multicolumn{10}{|c|}{ Monthly household income ("USD) } \\
\hline$<771$ & 1 & & & 1 & & & 1 & & \\
\hline $771-1543$ & 0.030 & $\begin{array}{l}1.030(0.763- \\
1.391)\end{array}$ & 0.845 & 0.520 & $\begin{array}{l}1.681(1.320- \\
2.142)\end{array}$ & $<0.001$ & 0.344 & $\begin{array}{l}1.411(0.988- \\
2.015)\end{array}$ & 0.058 \\
\hline$>1543$ & 0.095 & $\begin{array}{l}1.099(0.620- \\
1.949)\end{array}$ & 0.747 & 0.169 & $\begin{array}{l}1.184(0.735- \\
1.907)\end{array}$ & 0.487 & 0.627 & $\begin{array}{l}1.872(0.979- \\
3.579)\end{array}$ & 0.058 \\
\hline \multicolumn{10}{|l|}{ Education level } \\
\hline $\begin{array}{l}\text { Junior high school } \\
\text { or less }\end{array}$ & 1 & & & 1 & & & 1 & & \\
\hline $\begin{array}{l}\text { Senior high } \\
\text { school }\end{array}$ & -0.111 & $\begin{array}{l}0.895(0.613- \\
1.306)\end{array}$ & 0.564 & 0.022 & $\begin{array}{l}1.022(0.751- \\
1.391)\end{array}$ & 0.890 & 0.008 & $\begin{array}{l}1.008(0.657- \\
1.547)\end{array}$ & 0.971 \\
\hline College or more & 0.213 & $\begin{array}{l}1.237(0.780- \\
1.962)\end{array}$ & 0.365 & 0.115 & $\begin{array}{l}1.122(0.763- \\
1.650)\end{array}$ & 0.557 & 0.201 & $\begin{array}{l}1.222(0.720- \\
2.073)\end{array}$ & 0.457 \\
\hline \multicolumn{10}{|c|}{ Spouse's education level } \\
\hline $\begin{array}{l}\text { Junior high school } \\
\text { or less }\end{array}$ & 1 & & & 1 & & & 1 & & \\
\hline $\begin{array}{l}\text { Senior high } \\
\text { school }\end{array}$ & 0.050 & $\begin{array}{l}1.051(0.720- \\
1.536)\end{array}$ & 0.796 & 0.289 & $\begin{array}{l}1.335(1.009- \\
1.765)\end{array}$ & 0.043 & 0.516 & $\begin{array}{l}1.675(1.115- \\
2.515)\end{array}$ & 0.013 \\
\hline College or more & -0.019 & $\begin{array}{l}0.981(0.619- \\
1.556)\end{array}$ & 0.936 & 0.500 & $\begin{array}{l}1.649(1.233- \\
2.204)\end{array}$ & 0.001 & 0.681 & $\begin{array}{l}1.976(1.313- \\
2.973)\end{array}$ & 0.001 \\
\hline \multicolumn{10}{|c|}{ Artificial abortion history } \\
\hline No & 1 & & & 1 & & & 1 & & \\
\hline Yes & 1.009 & $\begin{array}{l}2.743(2.081- \\
3.615)\end{array}$ & $<0.001$ & 0.147 & $\begin{array}{l}1.159(0.716- \\
1.875)\end{array}$ & 0.549 & 0.269 & $\begin{array}{l}1.308(0.823- \\
2.081)\end{array}$ & 0.256 \\
\hline
\end{tabular}

OR odds ratio, $95 \%$ Cl 95\% confidence interval

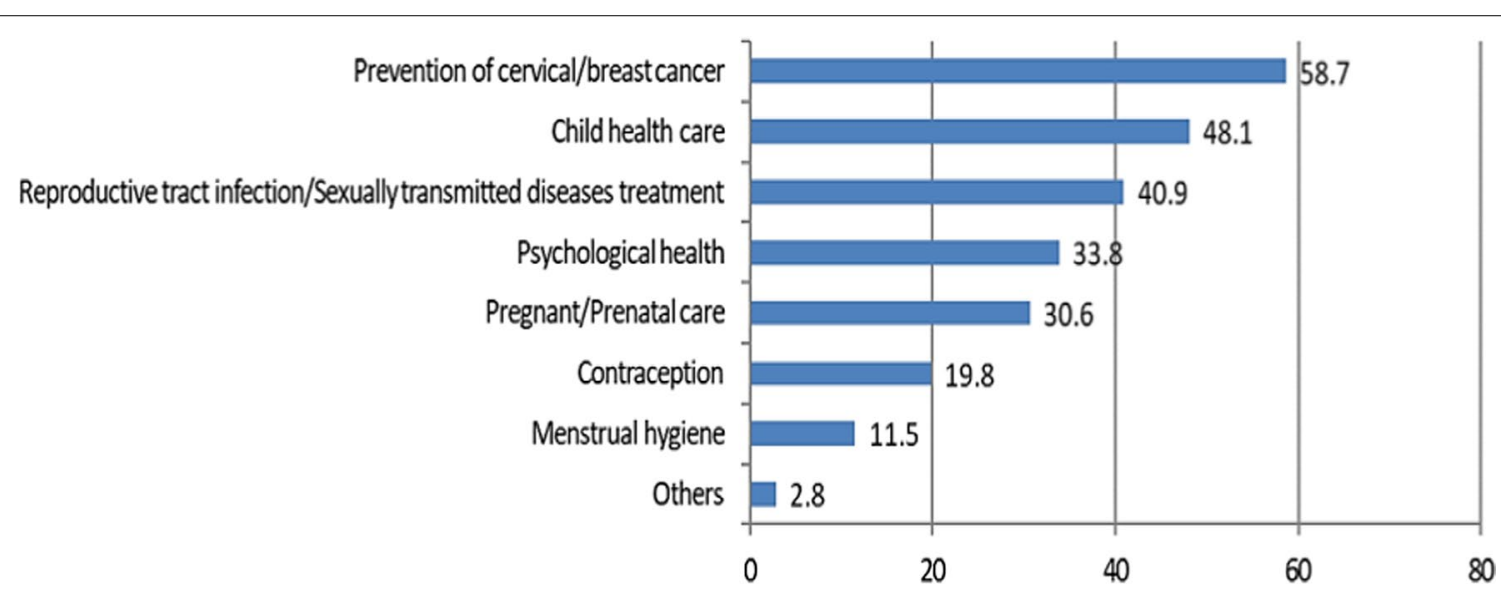

Fig. 1 The most desired RH services (reported as percentage of participants) 


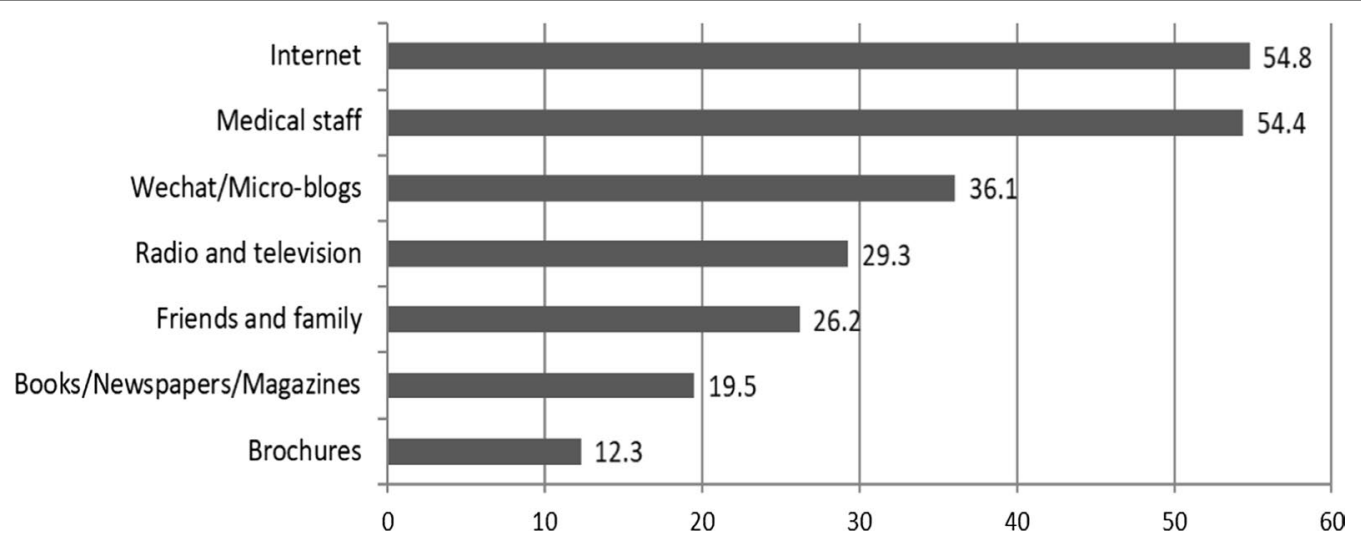

Fig. 2 The most preferred methods of obtaining RH service-related information (expressed as percentage of participants)

The least utilized RH service was preconception care $(27.5 \%)$. The utilization rate was lower than that measured among 12,309 women in Shanghai, China (40\%) [13]. The differences among these results may be explained as follows. First, in a study conducted in Shanghai, $56.2 \%$ of the participants had a college degree or above. However, in this study, only $24.7 \%$ of participants had a college education. Highly educated women might be aware of the importance of preconception care to promote maternal health [28]. Second, we recruited women from communities, whereas the previous study sampled from hospitals when the women presented for their initial prenatal visit. To some extent, we avoided sample bias. Third, China implemented the National Free Preconception Health Examination Project (NFPHEP) in 2011 to provide free preconception care in rural areas [29]. This finding may be attributed to insufficient policy advertisement, but more studies are needed to systematically evaluate the obstacles to NFPHEP implementation in low-income populations in China.

Additionally, we found that women aged 30-39 years were more likely to receive $\mathrm{RH}$ screening, which is consistent with previous studies conducted in China [14, 15]. Employed women exhibited better utilization of $\mathrm{RH}$ screening and related examinations in this study. The relationship between employment and the utilization of RH services has been insufficiently researched to date. In a study of 850 rural married women in Hainan Province, China, the level of RH knowledge of employed women was greater than that of the general population [30]. Wang [31] found that a high level of RH knowledge was associated with a positive attitude and behaviour. Although further research is necessary, healthcare providers could promote the utilization of $\mathrm{RH}$ services for target populations by improving the level of $\mathrm{RH}$ knowledge.
Remarkably, women whose spouses had a high education level were more likely to use $\mathrm{RH}$ screening and related examinations/services. Husbands can greatly influence decision-making process. An educated husband might be aware of the importance of $\mathrm{RH}$ services in promoting women's health and remind their partner to receive such services [22, 32, 33]. Our results reinforce the importance of targeting families with interventions, not just individual women.

In our study, women who had an artificial abortion history were more likely to use RH counselling. Previous studies on childbearing women found that only education level, region and service quality affected $\mathrm{RH}$ counselling use $[34,35]$. A possible reason is that, after artificial abortion, doctors may provide women with RH counselling services to avoid the next unintended pregnancy or provide guidance for their next pregnancy [36, 37].

The RH service most desired by participants in this study involved cervical/breast cancer prevention. This finding may be due to the fact that cervical cancer and breast cancer are the most common malignant tumours in women; thus, women hope to receive prevention services $[38,39]$. Our study also found that women preferred to access RH service-related information via the internet. The internet is an effective platform for improving health services due to the ease of obtaining information without time and space limitations [40-42]. Other methods of obtaining $\mathrm{RH}$ service-related information, such as lectures, brochures, magazines, video and television, should be highlighted as alternative methods to meet the needs of different groups, especially in underdeveloped areas that lack access to the internet.

\section{Strengths and limitations}

This was the first study based on a large sample of childbearing women in central rural China to investigate the 
utilization of and factors associated with $\mathrm{RH}$ services among childbearing women after implementation of the universal two-child policy. We selected four regions to control for sampling errors. Data collectors, individuals involved in quality control, and other personnel were thoroughly trained before the study. All of the participants were recruited from the community, which may have made the sample more representative and the findings more universally applicable.

There are some methodological limitations of this study. First, the data were retrospectively obtained and self-reported, and memory bias and concealment of information were possible. Second, our study only described the current use of and need for $\mathrm{RH}$ services given the cross-sectional design, and more intervention studies are needed to promote the use of RH services. Finally, $\mathrm{RH}$ is a problem involving multiple generations, i.e., grandmothers and mothers-in-law, and more research is needed to determine whether their attitudes influence women's decisions about whether to access RH services.

\section{Conclusion}

Although the Chinese government proposed plans to improve the use of RH services in rural areas, we demonstrated that challenges remain regarding the use of such services. The internet may be one of the best and most effective methods for enhancing RH knowledge and improving the use of RH services. Future efforts should target high-risk populations of women who are older, have a low income or low education level, or are unemployed as well as their families by providing them with $\mathrm{RH}$ service-related information and cultivating positive attitudes towards RH services.

\section{Abbreviations \\ RH: Reproductive health; UN: United Nations; SDG: Sustainable develop- ment goals; HPV: Human papillomavirus; NCSPRA: National Cancer Screening Program in Rural Areas.}

\section{Supplementary Information}

The online version contains supplementary material available at https://doi. org/10.1186/s12978-021-01182-z.

Additional file 1. Women's Reproductive Health Questionnaire.

\section{Acknowledgements}

We thank the participants in this study and acknowledge the outstanding support provided by Hunan Province and the local Women's Federation, Office of the Committee for Women and Children's Workers and Health Administration in Hunan Province, China. We also thank American Journal Experts [http:// bit.ly/AJE-HS] for English language editing.

\section{Authors' contributions}

JY conceived and designed the study and drafted the manuscript. YTM, CX, $\mathrm{SQ}, \mathrm{LF}$ and $\mathrm{MN}$ helped with the data collection and entry. YL revised the manuscript, contributing intellectual content. All authors read and approved the final manuscript.

\section{Funding}

The project was supported by the Hunan Women's Research Association, China (Grant No. 20YB03). The funding body was not responsible for the study design or data collection, analysis, or interpretation.

Availability of data and materials

Data are available upon request from the corresponding author.

\section{Declarations}

\section{Ethics approval and consent to participate}

The Ethics Committee of Xiang Ya Nursing School, Central South University approved the study. Written consent was obtained from all respondents before the interview.

\section{Consent for publication}

Not applicable.

\section{Competing interests}

The authors declare that they have no conflicts of interest.

Received: 2 November 2020 Accepted: 14 June 2021

Published online: 27 June 2021

\section{References}

1. Population and development: Programme of action adopted at the International Conference on Population and Development, Cairo, 5e13 September 1994. New York: United Nations, Dept. for Economic and Social Information and Policy Analysis; 1995.

2. Lv X, Yan B. Analysis of problems and promotion strategies of female reproductive health. Sci Health. 2019;7:234204.

3. Sepulveda J, Murray C. The state of global health in 2014. Science. 2014;345(6202):1275-8. https://doi.org/10.1126/science.1257099.

4. Glasier A, Gülmezoglu AM, Schmid GP, Moreno CG, Van Look PF. Sexual and reproductive health 1: sexual and reproductive health: a matter of life and death. Lancet. 2019;368(9547):1595-607. https://doi.org/10. 1016/S0140-6736(06)69478-6.

5. Sustainable Development Goals. The United Nations. https://www.un. org/sustainabledevelopment/health/. Accessed 30 Aug 2020.

6. World Demographics 2020 (Population, Age, Sex, Trends). Worldometer. https://www.worldometers.info/demographics/world-demographi cs/. Accessed 10 Oct 2020.

7. Chen M, Luo Y, Fu J, et al. Reproductive health status and related knowledge among women aged 20-39 years in rural China: a crosssectional study. Reprod Health. 2020;17(1):90. https://doi.org/10.1186/ s12978-020-00939-2.

8. Zeng Y, Hesketh T. The effects of China's universal two-child policy. Lancet. 2016;388(10054):1930-8. https://doi.org/10.1016/S0140-6736(16) 31405-2.

9. Wei Zhixin Yu, Dian LH. Trends and characteristics of induced abortion among married women of childbearing age in China: Based on the data of four national fertility sampling surveys from 1997 to 2017. Popul Res. 2020;44(06):79-95.

10. Zhang HX, Zhao YY, Wang YQ. Analysis of the characteristics of pregnancy and delivery before and after implementation of the two-child policy. Chin Med J (English). 2018;131(1):37-42. https://doi.org/10. 4103/0366-6999.221268.

11. Yang RC, Xiao YH, Xie XD, Gao YP, Hu ZH. Analysis on demand and utilization status of reproductive health service and influencing factors in rural married women of childbearing age. Matern Child Health Care China. 2013;28(27):4493-5. https://doi.org/10.7620/zgfybj.j.issn.10014411.2013 .28 .24 . 
12. DiBari JN, Yu SM, Chao SM, Lu MC. Use of postpartum care: predictors and barriers. J Pregnancy. 2014;2014: 530769. https://doi.org/10.1155/ 2014/530769.

13. Ding Y, Li XT, Xie F, Yang YL. Survey on the implementation of preconception care in Shanghai, China. Paediatr Perinat Epidemiol. 2015;29(6):492500. https://doi.org/10.1111/ppe.12218.

14. Yang XL. Study on screening rate of breast cancer and cervical cancer in women and related influencing factors. Electron J Pract Gynecol Endocrinol. 2016;3(18):134-6. https://doi.org/10.3969/j.issn.2095-8803.2016.18. 085.

15. Xiang QY. Analysis of influencing factors of willingness to screen for cervical cancer. Electron J Pract Gynecol Endocrinol. 2019;6(20):10-1, 20.

16. Report on the development of maternal and child health in China (2019). National Health Commission of the People's Republic of China. Department of maternal and child health, 2019. http://www.nhc.gov.cn/. Accessed 30 Aug 2020

17. Zhou Y, Wang T, Fu J, Chen M, Meng Y, Luo Y. Access to reproductive health services among the female floating population of childbearing age: a cross-sectional study in Changsha, China. BMC Health Serv Res. 2019:19(1):540. https://doi.org/10.1186/s12913-019-4334-4.

18. Chen N. Study on the change of childbearing status of women of childbearing age under the adjustment of childbearing policy_-based on the analysis of the dynamic monitoring data of birth population in the two provinces of central China. J Huazhong Univ Sci Technol (social science edition). 2019;33(04):37-46. https://doi.org/10.19648/j.cnki.jhustss1980. 2019.04 .06

19. Special provisions on labour protection of female workers. The Central People's Government of the People's Republic of China. 2012. http:// www.gov.cn/fffg/. Accessed at 20201/2/3.

20. Tian C, Peng H, Soowon L, Xu Y, Li YM, Zhu Q, et al. Analysis of maternal and child health care during pregnancy from 2012 to 2018. Chin J Woman Child Health Res. 2020;31(5):546-52. https://doi.org/10.3969/j. issn.1673-5293.2020.05.001

21. Wu BH, Jin CY, Wang HY, Li N, Li ZW. Analysis on the changes of elderly maternal and parity in a tertiary hospital in northern China since the "Universal Two-Child" policy. Chin J Reprod Health. 2018;29(3):201-4. https:// doi.org/10.3969/j.issn.1671-878X.2018.03.001.

22. Adams YJ, Smith BA. Integrative review of factors that affect the use of postpartum care services in developing countries. J Obstet Gyneco Neonat Nurs. 2018;47(3):371-84. https://doi.org/10.1016/j.jogn.2018.02. 006.

23. Wilcox A, Levi EE, Garrett JM. Predictors of non-attendance to the postpartum follow-up visit. Matern Child Health J. 2016;20(Suppl 1):22-7. https://doi.org/10.1007/s10995-016-2184-9.

24. Stumbras K, Rankin K, Caskey R, Haider S, Handler A. Guidelines and interventions related to the postpartum visit for low-risk postpartum women in high and upper middle income countries. Matern Child Health J. 2016;20(Suppl 1):103-16. https://doi.org/10.1007/s10995-016-2053-6.

25. Chinese Nutrition Society. National Nutrition Program (2017-2030). Acta Nutrimenta Sinica. 2017;39(4):315-20, 312. https://doi.org/10.3969/j.issn. 0512-7955.2017.04.002.

26. Siekmans K, Roche M, Kung'u JK, Desrochers RE, De-Regil LM. Barriers and enablers for iron folic acid (IFA) supplementation in pregnant women. Matern Child Nutr. 2018;14(Suppl 5): e12532. https://doi.org/10.1111/ men.12532.

27. $\mathrm{Hu} X \mathrm{~L}$, Li MD. Practice and active exploration to create a precise service brand of folic acid supplement and pre pregnancy eugenic health examination project. Chin J Fam Plan. 2017;25(6):417-9. https://doi.org/ 10.3969/j.issn.1004-8189.2017.06.017.
28. Hemsing N, Greaves L, Poole N. Preconception health care interventions: a scoping review. Sex Reprod Healthcare. 2017;14:24-32. https://doi.org/ 10.1016/j.srhc.2017.08.004.

29. Lu YS, Lu YH, Zhou YY. Influencing factors of utilization of pre pregnancy health care services for women of childbearing age in Jianghai District, Jiangmen City. Shenzhen J Integr Tradit Chin Western Med. 2019;29(06):196-8. https://doi.org/10.16458/j.cnki.1007-0893.2019.06.097.

30. Yang Z, Zhu J, Miao FY, Zhou YH, Li Q, Zhang J, et al. Study on reproductive health status and behaviour influencing factors of rural married women of childbearing age in Hainan Province. Chin J Public Health Manag. 2017;33(4):526-9. https://doi.org/10.19568/j.cnki.23-1318.2017. 04.025 .

31. Wang KH. Survey on reproductive health knowledge, attitude, behavior and needs of women of childbearing age. Chin Commun Phys. 2016;32(14):187-9. https://doi.org/10.3969/j.issn.1007-614x.2016.14.118.

32. Xiao X, Ngai FW, Zhu SN, Loke AY. The experiences of early postpartum Shenzhen mothers and their need for home visit services: a qualitative exploratory study. BMC Pregnancy Childbirth. 2019;20(1):5. https://doi. org/10.1186/s12884-019-2686-8.

33. Xu YW. Screening of breast and cervical cancer in women and related factors. China Health Vision. 2018;18:246. https://doi.org/10.3969/j.issn. 1005-0019.2018.18.358

34. Wen B. Investigation on the current situation of comprehensive sexual and reproductive health counselling among women of childbearing age. Fudan University. 2011

35. Wu SH. Practice and thinking of counselling and guidance on contraception and birth control at grass roots level. Chin J Fam Plan. 2013;21(10):703-6.

36. Jiang $H, X u$ J, Richards $E$, et al. Opportunities, challenges and systems requirements for developing post-abortion family planning services: perceptions of service stakeholders in China. PLoS ONE. 2017;12(10): e0186555. https://doi.org/10.1371/journal.pone.0186555.

37. Che Y, Dusabe-Richards E, Wu S, Jiang Y, Dong X, Li J, Zhang WH, Temmerman $M$, Tolhurst $R$, INPAC group. A qualitative exploration of perceptions and experiences of contraceptive use, abortion and post-abortion family planning services (PAFP) in three provinces in China. BMC Womens Health. 2017;17(1):113. https://doi.org/10.1186/s12905-017-0458-z.

38. Wilm J, Schüler-Toprak S, Ortmann O. Screening for cervical and breast cancer. Pathologe. 2016;37(5):477-89. https://doi.org/10.1007/ s00292-016-0228-y.

39. Torre LA, Islami F, Siegel RL, Ward EM, Jemal A. Global cancer in women: burden and trends. Cancer Epidemiol Biomark Prev. 2017;26(4):444-57. https://doi.org/10.1158/1055-9965.EPI-16-0858.

40. Sim I. Mobile devices and health. N Engl J Med. 2019;381(10):956-68. https://doi.org/10.1056/NEJMra1806949.

41. Arbour MW, Stec MA. Mobile applications for women's health and midwifery care: a pocket reference for the 21 st century. J Midwifery Womens Health. 2018;63(3):330-4. https://doi.org/10.1111/jmwh.12755.

42. Teitelman AM. Using mobile technologies to improve women's health. J Obstet Gynecol Neonatal Nurs. 2018;47(6):830-2. https://doi.org/10. 1016/j.jogn.2018.09.004

\section{Publisher's Note}

Springer Nature remains neutral with regard to jurisdictional claims in published maps and institutional affiliations. 